\title{
Investigating learning styles for adaptive Massaive Open Online Cource (MOOC) learning
}

\author{
Hasmaini Hashim ${ }^{1 *}$, Sazilah Salam ${ }^{2}$, Siti Nurul Mahfuzah Mohamad ${ }^{3}$ \\ 1, 2,3 Faculty of Information and Communication Technology, Universiti Teknikal Malaysia Melaka, Durian Tunggal, \\ Malaysia
}

\section{Keywords \\ Learner characteristics \\ Learning styles \\ MOOC \\ Second language}

Received: 15 November 2017 Accepted: 30 September 2017 Published: 9 October 2017

\begin{abstract}
This study aims to investigate the learning styles dimension of students in MOOC learning and propose a MOOC development model that is adaptive to learning styles. A mixed-method approach was adopted in this study to investigate the learning styles dimension of students in MOOC learning based on Felder and Silverman's (1988) Learning Style Model. Samples for the quantitative and qualitative studies were 50 and 20 students, respectively. The interview consists of 14 questions, and 11 students were involved in the interview. The results from the survey analysis revealed that the highest dimension among the eight learning styles is visual learner $76 \%$ while the result from the interview session is also confirmed visual (24.24). In order to propose a MOOC development model that is adaptive to students learning styles, a literature study was conducted. The study revealed the preferred learning styles dimensions and patterns proposed suitable for an adaptive MOOC content development model.
\end{abstract}

(C) 2017 The Author(s). Published by TAF Publishing.

\section{INTRODUCTION}

Learners' characteristics are important in all forms of online learning where there are three types of learner characteristics: (1) learning style, (2) cognitive style, and (3) multiple intelligence (Ashaari, 2017; Lever-Duffy et al., 2002; Park et al., 2015). Authors stated these types are the effective factor for student learning. As mentioned in Mohamad (2014), each student has their own learning style to be considered during the learning process. Figure 1, shows the types of learner characteristics.

According to Sadhasivam and BabuKalivaradhan (2017), learning styles are authentic as it is the appropriate techniques or methods in which learners learn, comprehend and get information. The authors highlight that learning styles are an approach to help enhance the rate and nature of learning. According to Bakar and Ali (2016), learning styles are the ways of receiving and responding to a learning stimulus with (1) unique psychological, (2) affective, and (3) cognitive composition. Learning styles refer to the variations in individual ability to accumulate as well as assimilate information, sensory preferences that impact learning and are related to personality (Abante et al., 2014; Bakar and Ali,

\footnotetext{
*Corresponding author: Hasmaini Hashim

${ }^{\dagger}$ Email: hasmainie76@gmail.com
} 
2016; Kongmanus, 2016; Lever-Duffy et al., 2002). However, according to Fasihuddin et al. (2017), learning styles refer to the manner in which learners receive and perceive information. In year 2016, Bakar and Ali (2016) listed three important relationship elements for learning styles: (1) academic achievements, (2) attitudes toward learning, and (3) multimedia technology.

The objective in this study is to investigate the learning styles used in MOOC in Mandarin and the research question is: What are the learning styles of learners that are used in Mandarin MOOC? From the findings of this study, the researchers propose a content development model in MOOC based on learning styles.

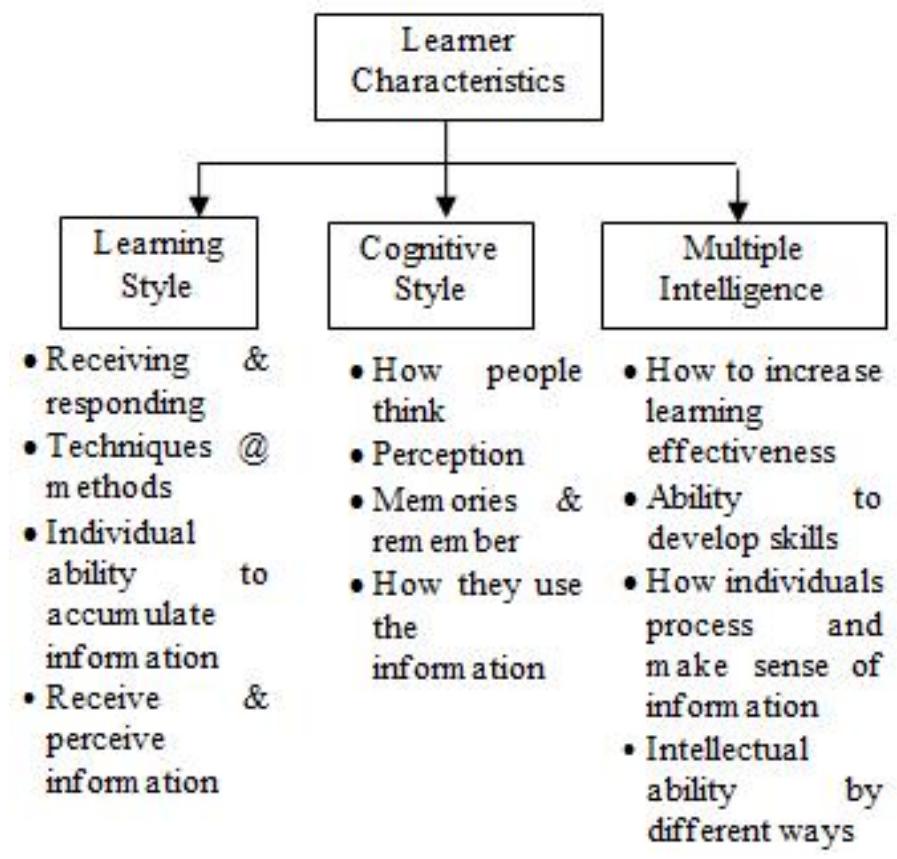

FIGURE 1. Types of learner characteristics

\section{REVIEW OF RELATED LITERATURE}

MOOCs have a large heterogeneous population of learners and each learner has a: (1) different learning style, and (2) different learning approach (Arora et al., 2017). Previous studies have reported a few learning style models to build up pedagogical hypothesis: (1) Kolb Experiential Learning Theory, (2) VARK Model, (3) Felder and Silverman (1988) learning/teaching style model, and (4) Dunn and Dunn Learning Style Mode (Sadhasivam and BabuKalivaradhan, 2017). Authors highlight that the Felder and Silverman Learning Styles Model has been selected as the most appropriate model for open learning (Fasihuddin et al., 2017).

Previous studies found that there were four different dimensions of learning styles: (1) processing (active/reflective), (2) perception (sensing/intuitive), (3) input (visual/verbal), and (4) understand (sequential/global) (Hone and Said, 2016; Al-Azawei et al., 2017; Fasihuddin et al., 2017; Hmedna et al., 2016). Rohaniyah (2017), stated the major differences in learning style are (1) the way people perceived (sensation versus intuition), (2) the way they made decisions (logical thinking versus imaginative feelings), and (3) how active or reflective they were while interacting (extroversion versus introversion). Felder and Silverman (1988) stated that engineering students tend to prefer active, sensing, visual, and sequential styles (Al-Azawei et al., 2016; Alahoul et al., 2016). Since 2004, author 
stated more than 71 learning style models in which each model was based on particular dimensions. In the paper, the Felder and Silverman (1988) learning/teaching style model was used as learning styles model in MOOC.

TABLE 1. Summary of learning style by dimension

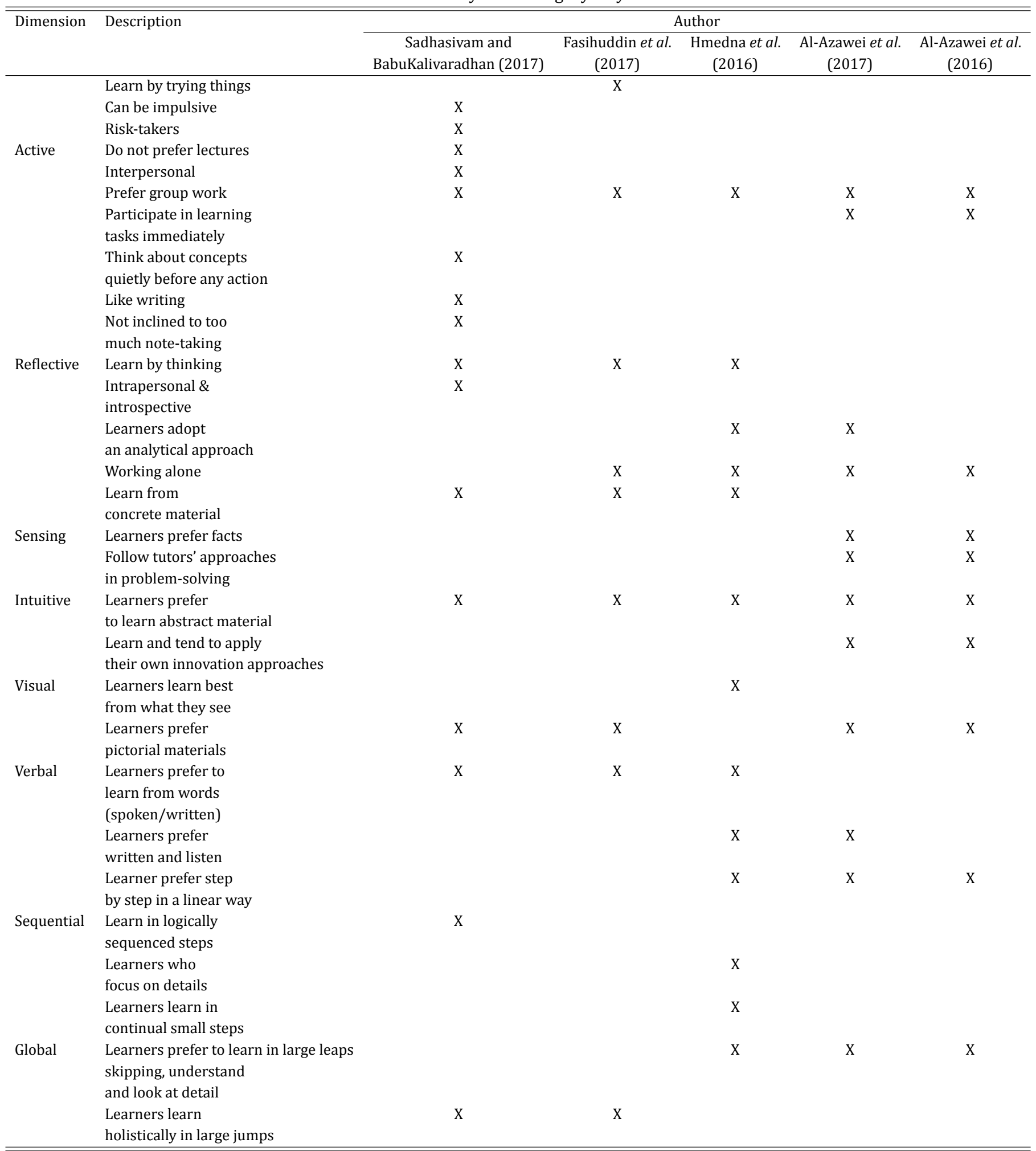


Previous research has shown that even though engineering students prefer active, sensing, visual, and sequential learning as do other students from different backgrounds, they can adapt to a learning context even if their preferences are not met (Al-Azawei et al., 2016). In 2015, researchers mentioned, the different learning styles may affect student success in online courses (Chang et al., 2015). This paper aims to study the relationship between learning styles and academic achievements in MOOC. Table 1 shows the summary of learning styles by dimension and Figure 2 shows the dimensions of learning styles.

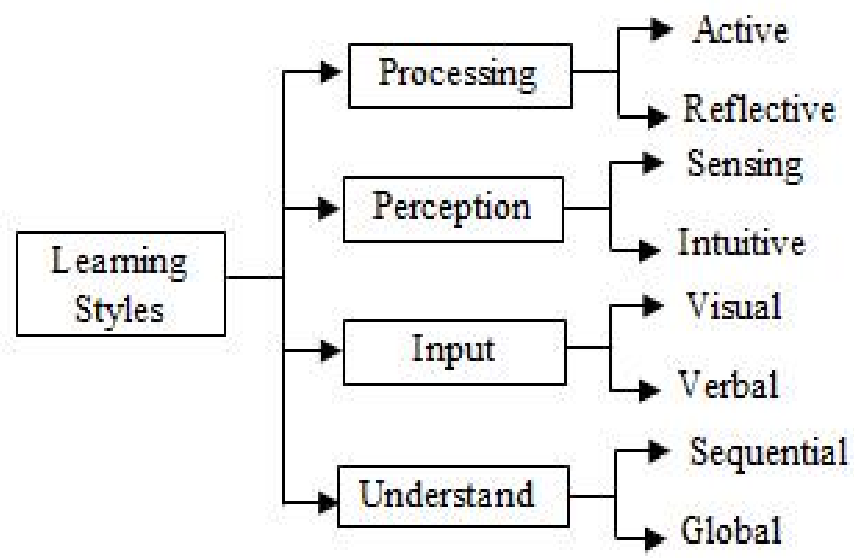

FIGURE 2 . Dimension of learning styles

\section{MATERIALS AND METHODS \\ Method}

A mixed-method involving both quantitative and qualitative research methods was adopted in this study. The quantitative data were collected using a survey, involving 50 students from a public university in Malaysia. The qualitative data were collected from the interview while quantitative data was collected through the students' questionnaires. Moreover, semi-structured interviews were conducted with the students in an attempt to obtain students' experiences and their opinions on MOOC assessment.

\section{Participants}

The participants in the research were 50 technical students in a public university in Malaysia. The study found the numbers of male students are more than female students. Table 2 shows the percentages and number of participant. However, the data obtained are consistent for both genders.

TABLE 2 . Percentages and number of participants

\begin{tabular}{lcccc}
\hline \hline Gender & \multicolumn{2}{c}{ Survey } & \multicolumn{2}{c}{ Interview } \\
\cline { 2 - 5 } & Male & Female & Male & Female \\
\hline No. of participants & 27 & 23 & 5 & 6 \\
Percentages & 54.00 & 46.00 & 45.45 & 54.55 \\
\hline \hline
\end{tabular}


Figure 3 shows the percentages of survey participants by faculty.

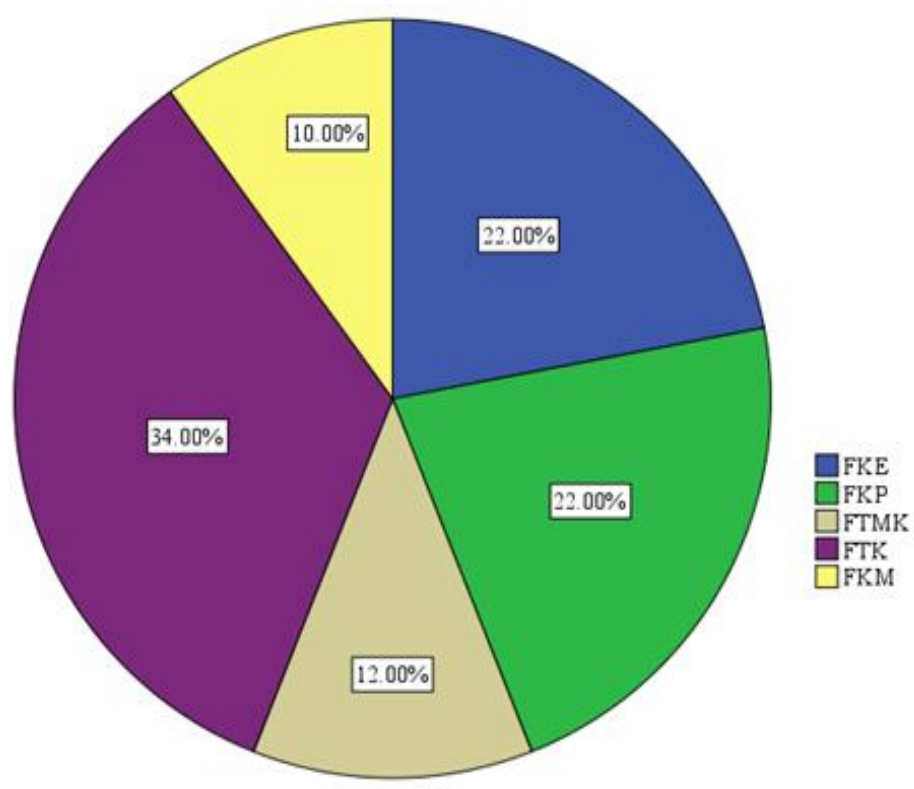

FIGURE 3 . Percentages of participants by faculty

In addition to these, the participants for the semi-structured interviews were also selected randomly. There were students studying at all faculties of the university who participated in the interviews. Figure 4 shows the percentages of interview participants by faculty.

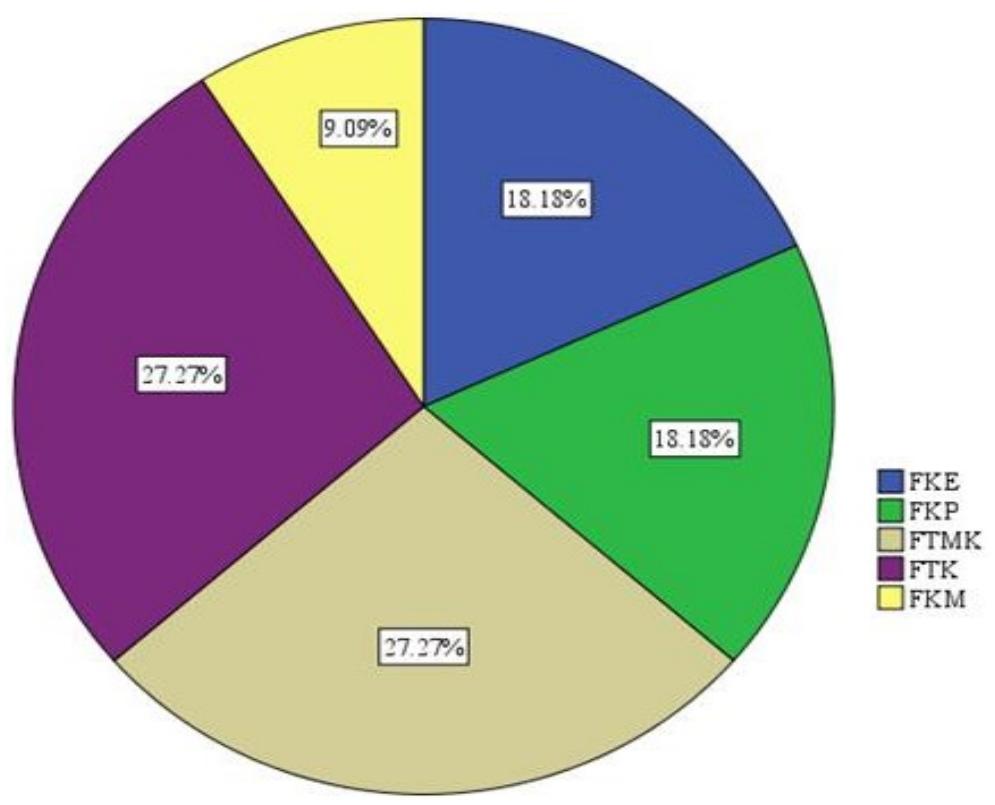

FIGURE 4 . Percentages of participants by faculty

\section{Research Instruments}

Questionnaire and interview are used as the research instrument to investigate this study. 
eight dimensions of learning styles. The survey items were adopted from several research projects with similar research scope (Drucker, 1993; Kintakaningrum, 2012).

The interview was conducted using 14 items. Based on the students answers, the researcher conducted an affinity analysis to identify learner characteristics based on the 8 constructs and dimensions of learning styles. The interviews are to obtain students' experiences and their opinions on assessment of MOOC.

The purpose of both these methods is to identify learning styles in MOOC for assessment using OpenLearning platform. Thus, the interview questions are constructed to obtain students' experiences and their opinion on the MOOC assessment. The objective of this study is to investigate the existing learning styles in learning Mandarin via MOOC. Table 3 shows the research instrument used in this study.

TABLE 3. Research instrument

\begin{tabular}{lll}
\hline \hline Research Instrument & Construct & Item \\
\hline Questionnaire & Active, Reflective, & Question 1 to Question 20 \\
& Sensing, Intuitive, & \\
& Visual, Verbal, & \\
& Sequential, Global & \\
& Active, Reflective, Sensing, & Question 1 to Question 14 \\
Interview & Intuitive, Visual, & \\
& Verbal, Sequential, Global & \\
\hline \hline
\end{tabular}

\section{Data Analysis}

The data were analyzed by using frequency and percentages analysis. In the process of data analysis, the collected data are triangulated in the mixed-method approach to study the learning styles in using Mandarin MOOC.

\section{RESULTS AND DISCUSSION Questionnaire}

The findings of the questionnaires indicated that visual and active have the highest percentages among the learning styles for students based on the Felder and Silverman (1988) Learning Style Model in Mandarin MOOC. Figure 5 shows the dimensions of learning styles by frequency and percentages.

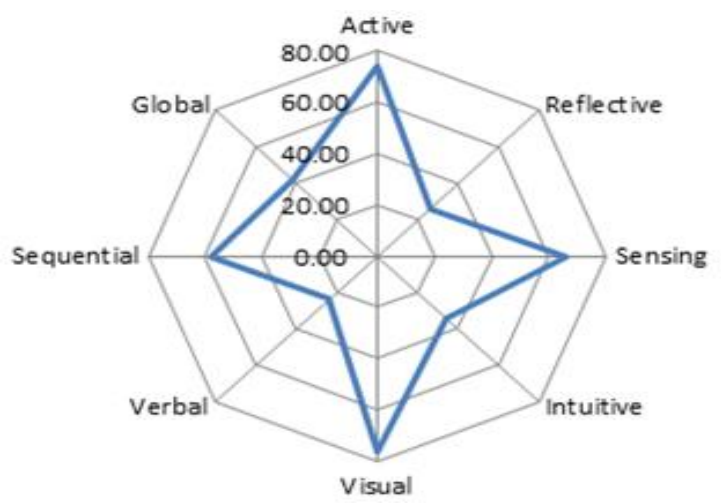

FIGURE 5. Dimension of learning styles by frequency and percentages 
According to the result of learner characteristic questionnaire, Table 4 shows the dimensions of learning styles by frequency and percentages in second language course. Visual learning has the highest frequency and percentage, the values are 38 and $76.00 \%$.

TABLE 4. Dimension of learning styles

\begin{tabular}{lcc}
\hline \hline Dimension & Frequency & Percentages (\%) \\
\hline Visual & 38 & 76.00 \\
Active & 37 & 74.00 \\
Sensing & 33 & 66.00 \\
Sequential & 29 & 58.00 \\
Global & 21 & 42.00 \\
Intuitive & 17 & 34.00 \\
Reflective & 13 & 26.00 \\
Verbal & 12 & 24.00 \\
\hline \hline
\end{tabular}

Table 5 shows the different dimensions of learning styles by frequency and percentages in second language course. The highest different dimension of learning styles is $\mathrm{AS}_{\mathrm{en}} \mathrm{V}_{\mathrm{i}} \mathrm{S}_{\mathrm{eq}}$ (Active, Sensing, Visual, Sequential), the values are 14 and 28.00\%. The lowest different dimension of learning styles is RNVG (Reflective, Intuitive, Verbal, Global). The percentage for dimension RNVG is zero (frequency $=0$ ).

TABLE 5 . Different dimension of learning styles

\begin{tabular}{lcc}
\hline \hline Dimension & Frequency & Percentages (\%) \\
\hline Active, Sensing, Visual, Sequential & & \\
$\left(\mathrm{A}, \mathrm{S}_{\mathrm{en}}, \mathrm{V}_{\mathrm{i}}, \mathrm{S}_{\mathrm{eq}}\right.$ ) & 14 & 28.00 \\
Active, Sensing, Visual, Global & 8 & 16.00 \\
Active, Intuitive, Visual, Global & 6 & 12.00 \\
Reflective, Sensing, Visual, Sequential & 4 & 8.00 \\
Active, Sensing, Verbal, Sequential & 3 & 6.00 \\
Active, Intuitive, Visual, Sequential & 3 & 6.00 \\
Reflective, Intuitive, Verbal, Sequential & 3 & 6.00 \\
Reflective, Sensing, Verbal, Global & 2 & 4.00 \\
Reflective, Intuitive, Visual, Global & 2 & 4.00 \\
Active, Sensing, Verbal, Global & 1 & 2.00 \\
Active, Intuitive, Verbal, Sequential & 1 & 2.00 \\
Active, Intuitive, Verbal, Global & 1 & 2.00 \\
Reflective, Sensing, Visual, Global & 1 & 2.00 \\
Reflective, Intuitive, Visual, Sequential & 1 & 2.00 \\
Reflective, Sensing, Verbal, Sequential & 0 & 0.00 \\
Reflective, Intuitive, Verbal, Global & 0 & 0.00 \\
\hline \hline
\end{tabular}

The different dimensions of learning styles are by percentages shown in Figure 6. The findings of the questionnaires indicated that Active, Sensing, Visual and Sequential $\left(\mathrm{AS}_{\mathrm{i}} \mathrm{V}_{\mathrm{en}} \mathrm{S}_{\mathrm{eq}}\right)$ dimensions are the learning styles for the students in second language course. 


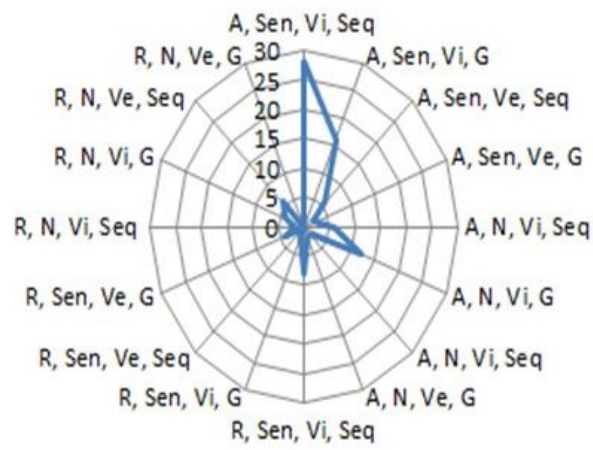

FIGURE 6. Percentages of different dimension learning style

Interview

According to the results of learner characteristics interview, Table 6 shows the dimensions of learning styles by percentages. Visual style has the highest percentage, the value is $24.24 \%$ in students' experiences and their opinions on MOOC assessment. Based on the interview, two elements in visual styles are identified; (1) learn best from what they see, and (2) learners prioritize pictorial materials.

TABLE 6. Dimension of learning styles by percentages

\begin{tabular}{lc}
\hline \hline Dimension & Percentages (\%) \\
\hline Visual & 24.24 \\
Active & 18.18 \\
Sensing & 18.18 \\
Reflective & 15.15 \\
Verbal & 9.09 \\
Sequential & 9.09 \\
Intuitive & 6.06 \\
Global & 0.00 \\
\hline \hline
\end{tabular}

To summarize, the findings of the mixed-method show that visual and active dimensions have the highest percentages of learning styles in second language course. The results from the survey analysis revealed that the highest dimension among the eight learning styles is visual learning $76 \%$ while the result from interview session has also confirmed visual (24.24). Figure 7 shows the summary of preliminary result for learning styles when using MOOC in second language. This study indicates that visual learning is the type of learning style of learners that used Mandarin MOOC.

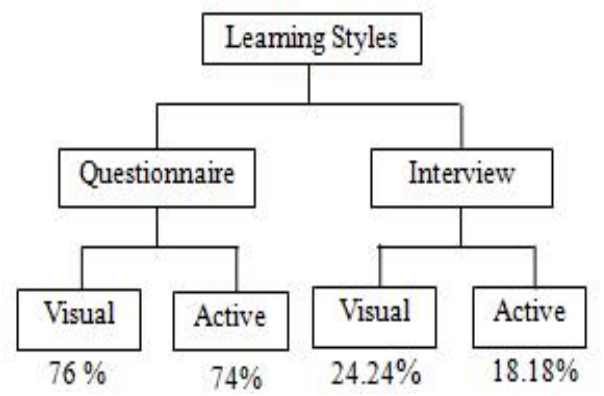

FIGURE 7. Summary of preliminary result for learning styles 
Table 7 shows the investigation of the existing learning styles in learning Mandarin via MOOC with both methods. The results from the survey analysis revealed that the dimensions for learning styles are Active, Sensing, Visual, and Sequential $\left(\mathrm{AS}_{\mathrm{i}} \mathrm{V}_{\text {en }} \mathrm{S}_{\text {eq }}\right)$ while the result from interview session also confirmed Active, Sensing, Visual, and Sequential.

TABLE 7 . Existing of learning styles

\begin{tabular}{lc}
\hline \hline \multicolumn{2}{c}{ Percentages (\%) } \\
\hline Questionnaire & Interview \\
\hline Active, Sensing, Visual, & Visual $=24.24$, Active $=18.18$, \\
Sequential (ASenViSeq) $=28.00$ & Sensing $=18.18$, Sequential $=9.09$ \\
\hline \hline
\end{tabular}

Figure 8 shows the interaction between dimensions of learning styles of technical student's who learn using MOOC. The dimension of learning styles is ASenViSeq (Active, Sensing, Visual, Sequential) that is used in Mandarin MOOC. The result is supported by Felder and Silverman (1988), engineering students tend to prefer active, sensing, visual, and sequential styles compared to another style dimension (Al-Azawei et al., 2016).

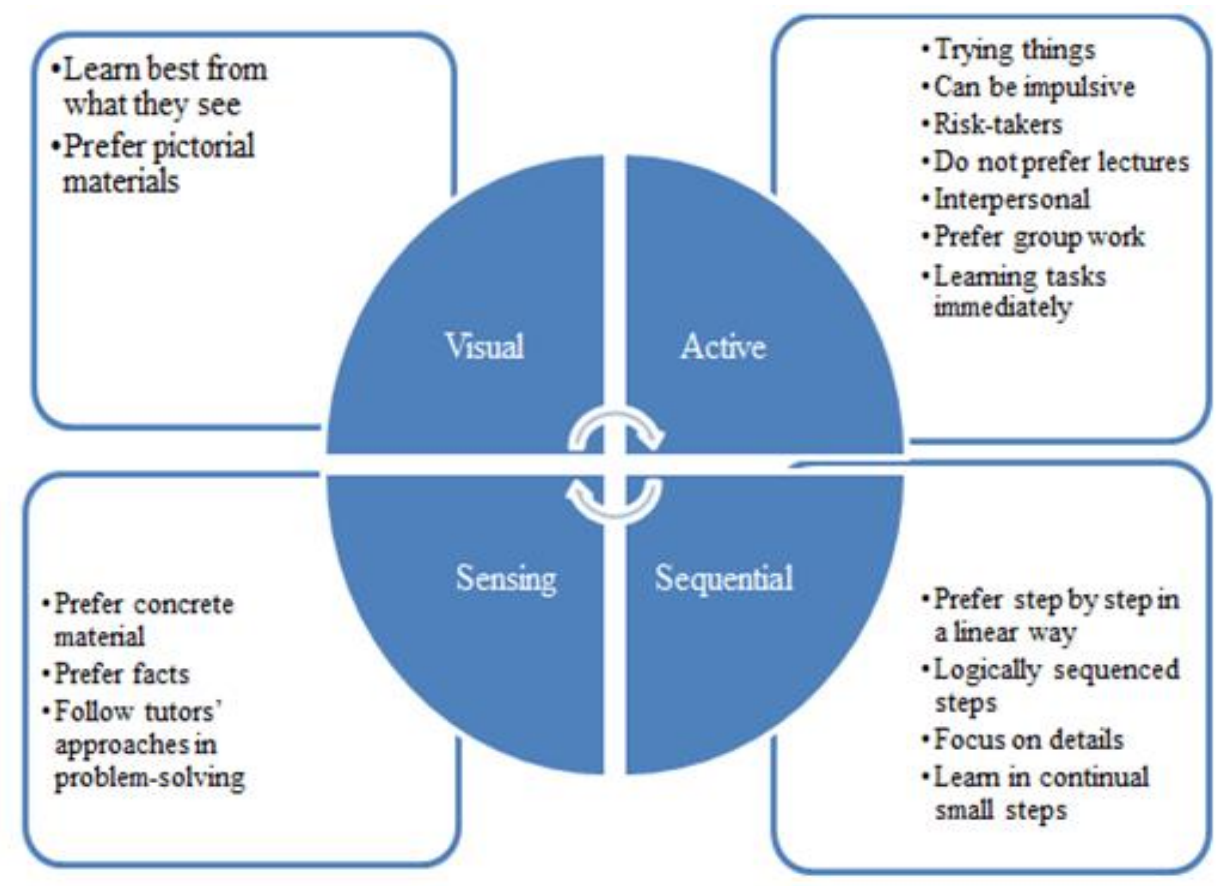

FIGURE 8 . Interaction between dimensions for learning styles

Finding shows the content development model for learning styles that uses MOOC. This model is developed based on interaction between dimensions of learning styles of technical student's who learn using MOOC. The researchers identify learning styles based on the four dimensions of learning styles. The Figure 9 shows the content development model for learning styles. 


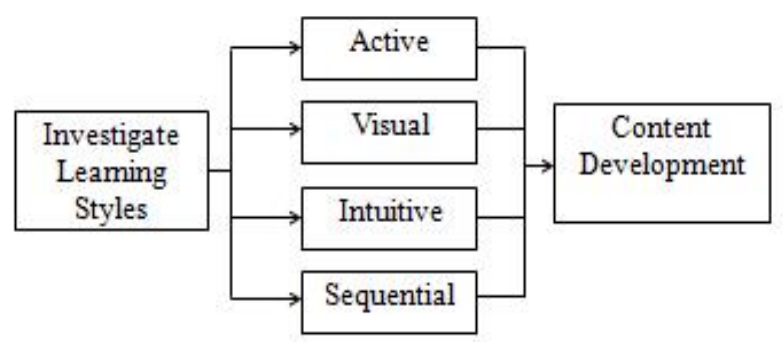

FIGURE 9. Content development model for learning styles

\section{CONCLUSION}

This initial study identified the learning styles of learners in using Mandarin MO0C. The findings of the questionnaire and interview indicate that visual and active are learner dimensions of learning styles. The results from the percentage analysis revealed that out of the eight learning styles dimensions, the preferred dimensions are visual learning followed by active learning.

\section{LIMITATIONS AND RECOMMENDATIONS}

This study is a small step, and it has a lot of potential for improvement. In future study, researchers aim to propose an effectiveness assessment model in MOOC based on learning styles.

\section{ACKNOWLEDGMENT}

This research is conducted by the Pervasive Computing \& Educational Technology Research Group, C-ACT, Universiti Teknikal Malaysia Melaka (UTeM), and supported by the Ministry of Higher Education (MOHE). FRGS grant: FRGS/1/2016/ICT01/FTMK-CACT/ F00327.

\section{REFERENCES}

Abante, Mark Enrick R., Benjie C. Almendral, J. Manansala, and Jovielyn Mañibo. 2014. Learning styles and factors affecting the learning of general engineering students. International Journal of Academic Research in Progressive Education and Development 3, no. 1: 16-27. DOI: 10.6007/ijarped/v3-i1/500

Alahoul, Mohammed Raheel Mohammed, Nurdiana Azizan, and Najwa Hayaati Alwi. 2016. Factors that affect the use of Malaysian e-learning websites by visually impaired users in the transfer of Islamic knowledge. Journal of Advanced Research in Social Sciences and Humanities 1, no. 1: 30-40. D0I: 10.26500/jarssh-01-2016-0104

Al-Azawei, Ahmed, Ali Al-Bermani, and Karsten Lundqvist. 2016. Evaluating the effect of Arabic engineering students' learning styles in blended programming courses. Journal of Information Technology Education: Research 15, no. 2: 109-130. DOI: 10.26500/jarssh-01-2016-0104

Al-Azawei, Ahmed, Patrick Parslow, and Karsten Lundqvist. 2017. Investigating the effect of learning styles in a blended e-learning system: An extension of the Technology Acceptance Model (TAM). Australasian Journal of Educational Tech nology 33, no. 2: 55-67. D0I: 10.14742 /ajet.2741

Arora, Skand, Manav Goel, A. Sai Sabitha, and Deepti Mehrotra. 2017. Learner groups in massive open online courses. American Journal of Distance Education 31, no. 2: 80-97. DOI: 10.1080/08923647.2017.1300461

Ashaari, Muhamad Faisal. 2017. The adoption and adaptation of online learning models in the framework of online da'wah. International Journal of Humanities, Arts and Social Sciences 3, no. 1: 1-8. D0I: 10.20469/ijhss.3.20001-1

Bakar, Zainudin Abu, and Rafaquat Ali. 2016. Learning style construct in student's learning. Mimbar Pendidikan 1, no. 2: 213-222. DOI: 10.17509/mimbardik.v1i2.3933

Chang, Ray I., Yu Hsin Hung, and Chun Fu Lin. 2015. Survey oflearning experiences and influence of learning style prefer- ences on user intentions regarding MOOCs. British Journal of Educational Technology 46, no. 3: 528-541. 
DOI: $10.1111 /$ bjet.12275

Drucker, Peter F. 1993. Managing for the future. New York, NY: Routledge.

Fasihuddin, Heba, Geoff Skinner, and Rukshan Athauda. 2017. To wards adaptive open learning environments: Evaluat ing the precision of identifying learning styles by tracking learners' behaviours. Education and Information Technolo gies 22, no. 3: 807-825.

Felder, Richard M., and Linda K. Silverman. 1988. Learning and teaching styles in engineering education. Engineering Education 78, no. 7: 674-681.

Hmedna, Brahim, Ali El Mezouary, Omar Baz, and Driss Mammass. 2016. A machine learning approach to identify and track learning styles in MOOCs. Paper presented at $5^{\text {th }}$ International Conference Multimedia Computing and Systems (ICMCS), Marrakech, Morocco.

Hone, K.S. and El Said, G.R. 2016. Exploring the factors affecting MOOC retention: A survey study. Computers \& Education, 98: 157-168.

Kintakaningrum, Tarisa Makina. 2012. Development and evaluation of individual and group learning performance using mobile supported learning management system. Ph.D. dissertation, Universiti Teknikal Malaysia Melaka, Durian Tunggal, Malaysia.

Kongmanus, Kobsook. 2016. Development of project-based learning model to enhance educational media business ability for undergraduate students in educational technology and communications program. Journal of Advances in Humanities and Social Sciences 2, no. 5: 287-296. D0I: 10.20474/jahss-2.5.5

Lever-Duffy, Judy, Jean McDonald, and Al Mizell. 2002. The 21 ${ }^{\text {st }}$-century classroom: Teaching and learning with technolo-

gy. Boston, MA: Addison-Wesley Longman Publishing Comapny.

Mohamad, Siti Nurul Mahfuzah. 2014. Model for online teaching tools based on interpersonal, visual and verbal intellige-

nce. $\mathrm{PhD}$ dissertation, Universiti Teknikal Malaysia Melaka, Durian Tunggal, Malaysia.

Park, Yeonjeong, Insung Jung, and Thomas C. Reeves. 2015. Learning from MO0Cs: A qualitative case study from the learn- $\quad$ ers' perspectives. Educational Media International 52, no. 2: 72-87. DOI: 10.1080/09523987.2015.1053286

Rohaniyah, Jaftiyatur. 2017. Integrating learning style and multiple intelligences in teaching and learning process. Wacana Didaktika 5, no. 1: 19-27.

Sadhasivam, Jayakumar, and Ramesh BabuKalivaradhan. 2017. MOOC: A framework for learners using learning style. International Education and Research Journal 3, no. 2: 21-24.

— This article does not have any appendix. - 